\title{
O IMPACTO DAS POLÍTICAS DE EVENTOS NO CLIMA ORGANIZACIONAL
}

\section{THE IMPACT OF POLICY OF EVENTS IN THE ORGANIZATIONAL CLIMATE}

\section{Maria do Carmo Ferreira Lima}

Mestre em Administração pela Universidade Nove de Julho - UNINOVE

Professora da Faculdade de Tecnologia de São Paulo - FATEC/SP

E-mail: mariadocarmo29@yahoo.com.br (Brasil)

\section{Gabriela Duarte}

Graduada do Curso de Automação de Escritórios e Secretariado da Faculdade de Tecnologia de São Paulo - FATEC/SP

E-mail: gabih.rock@ gmail.com (Brasil)

\section{Aline Araujo}

Graduada do Curso de Automação de Escritórios e Secretariado da Faculdade de Tecnologia de São Paulo - FATEC/SP

E-mail: lih.saraujo@gmail.com (Brasil)

\section{Maria Cecília Paiva}

Graduada do Curso de Automação de Escritórios e Secretariado da Faculdade de Tecnologia de São Paulo - FATEC/SP

E-mail: mariacecilia_paiva@hotmail.com (Brasil) 


\title{
O IMPACTO DAS POLÍTICAS DE EVENTOS NO CLIMA ORGANIZACIONAL
}

\section{RESUMO}

Focando cada vez mais as relações pessoais e o indivíduo, as organizações têm constatado a necessidade de um clima organizacional positivo para seu bom desempenho e desenvolvimento. Ao considerar as políticas de eventos como uma ferramenta motivacional e de incentivo à relação interpessoal, na pesquisa pretende-se aprofundar no assunto para estabelecer uma relação entre a utilização de tais práticas e seu impacto na geração de um ambiente de trabalho favorável. A realização da pesquisa deu-se em duas fases: uma de natureza exploratório-bibliográfica e outra de natureza quantitativa descritiva. Com a aplicação dos questionários foi verificado que as organizações não priorizam as necessidades e expectativas de seus funcionários, esquecendo que eles são recursos essenciais. Embora os colaboradores reconheçam que seu nível de motivação e integração são elevados com as aplicações de práticas de eventos e, além disso, afirmaram que há influências destas práticas em todo o clima da organização, são poucas as empresas que as adotam como ferramenta estratégica. Verificou-se ainda a grande disparidade existente entre a frequência e a influência desses eventos no cenário corporativo, que demonstraram a falta de conhecimento das organizações quando foi tratado na pesquisa sobre a opinião de seus colaboradores. Assim com os resultados da pesquisa observou-se que se as organizações investissem nos eventos corporativos com foco nos funcionários, conseguiriam elevar o estado de motivação de seus empregados.

Palavras-chave: Eventos; Comportamento Organizacional; Motivação.

\section{THE IMPACT OF POLICY OF EVENTS IN THE ORGANIZATIONAL CLIMATE}

\begin{abstract}
Focusing more the personal relationships and the individual, the organizations have realized the need for a positive organizational climate for their good performance and development. Considering the policy of events as a motivational tool and of encouragement to interpersonal relationship, we will discuss the subject in deep parameters to establish a link between the use of such practices and their impact on the generation of a favorable working environment. The research was conducted in two stages: one of exploratory-bibliographical nature and the other of quantitative descriptive nature. With the application of questionnaires we found that organizations are not giving priority to the needs and expectations of their employees, forgetting that they are essential resources. Though employees recognize that their level of motivation and integration is raised with the application of practices of events and, moreover, they affirm that there are influence of these practices throughout the organizations climate, there are few companies that adopt it as strategic tool. We also verified the significant gap between the frequency and the impact of these events in the corporate landscape, demonstrating the lack of knowledge of the organizations when dealing with the opinion of their employees. If organizations invest in corporate events with a focus on workers, they could raise the state of motivation of their employees.
\end{abstract}

Keywords: Events; Organizational Behavior; Motivation.

Revista de Gestão e Secretariado - GeSec, São Paulo, v. 5, n. 1, p 131-145, jan./abr. 2014. 


\section{INTRODUÇÃ̃o}

As empresas competem em seus respectivos segmentos em busca de melhores resultados. Segundo Hitt, Ireland e Hoskisson (2002, p. 8) as empresas que não dispõem de uma vantagem competitiva, ou que não estejam concorrendo em um setor atraente, obtém, no máximo, apenas retornos médios. Para Hitt, Ireland e Hoskisson (2002, p. 103) as decisões tomadas por administradores em termos de recursos, capacidades e competências essenciais têm influência significativa sobre a habilidade de uma empresa em desenvolver vantagens competitivas e auferir retornos superiores à média. Bohlander, Snell e Sherman (2005, p. 9) argumentam que o capital humano é intangível e não pode ser gerenciado da mesma maneira que as empresas gerenciam cargos, produtos e tecnologias. Uma das razões para isso é que são os funcionários, e não a empresa, os detentores do capital humano.

Segundo Luz (2001) o clima organizacional retrata o grau de satisfação material e emocional das pessoas no trabalho. Observa-se que o clima organizacional influencia a produtividade do indivíduo e, consequentemente da empresa. Bohlander, Snell \& Sherman (2005, p. 487) consideram que a capacidade de integrar os negócios e as preocupações dos funcionários é realmente rara, e fazer isso de forma a acrescentar valor para os clientes é especialmente admirável. As articulistas deste trabalho acreditam que o clima organizacional favorável tende a proporcionar motivação e interesse nos colaboradores, além de uma boa relação entre os funcionários e a empresa. Ao se decidir pela organização de um evento, a empresa deve definir os objetivos deste, ou seja, o que se pretende de resultados quantitativos e qualitativos. $\mathrm{O}$ foco de estudo nesta pesquisa são os eventos voltados para o público interno, relacionados ao endomarketing, que impactam, diretamente no clima da organização. Moscovici (1997) afirma que a maneira de lidar com as diferenças individuais cria certo clima entre as pessoas e tem forte influência sobre toda a vida em grupo, principalmente nos processos de comunicação, relacionamento interpessoal no comportamento organizacional e na produtividade. Sendo assim, o relacionamento interpessoal pode trazer satisfações ou insatisfações, que repercutem na organização em sua totalidade.

Nesse sentido, esta pesquisa tem como objetivo geral estudar o impacto que a Política de Eventos tem sobre o clima organizacional. Os objetivos específicos são: definir política de eventos no contexto organizacional e verificar a influência das políticas de eventos como ferramenta do endomarketing e seus resultados no clima organizacional.

Revista de Gestão e Secretariado - GeSec, São Paulo, v. 5, n. 1, p 131-145, jan./abr. 2014. 


\section{FUNDAMENTAÇÃO TEÓRICA}

\subsection{CONCEITOS DE EVENTOS E POLÍTICA DE EVENTOS}

Andrade (1999, p. 119) define evento de forma simples, "atividade dos mais diferentes tipos reunindo pessoas". Originária do latim, "eventu", pode-se conceituar a palavra como "acontecimento", que, por sua vez, vem do latim "contigescere”, ou seja, ser ou constituir fato de importância na vida social ou em outros âmbitos. Assim, pode-se definir evento como uma iniciativa que tenha o objetivo de reunir pessoas para diversas finalidades específicas que justifiquem sua realização, como: comemorações, festividades, intercâmbio de conhecimentos e experiências, troca de informações etc.

Possíveis falhas, ocasionadas pela falta de conhecimento técnico do profissional escolhido, poderão encadear uma série de erros que prejudicarão a imagem que o público externo e interno têm sobre a empresa. Segundo Cesca (2008, p. 49), “a organização de eventos é trabalhosa e exige grande responsabilidade. Acontece 'Ao vivo', e qualquer falha comprometerá o conceito/imagem da organização para a qual é realizado e do seu organizador".

De acordo com Phillips, Myhill e McDonough (2008), existem cinco tipos de necessidades: de ganhos (aumento nos lucros ou diminuição nos custos); de negócios (estabelece ganho potencial); de desempenho (desempenho específico do colaborador ou participante que não atende ao esperado); de aprendizado (implica entender o processo, o procedimento ou política), e de preferência (como, onde e quando um evento será realizado).

Feita a análise das necessidades, serão determinados os objetivos que possibilitarão o estabelecimento de metas a serem atingidas pelos participantes envolvidos no planejamento do evento, tornando o processo mais organizado e, por consequência, menos passível de erros. Ainda segundo Phillips, Myhill e McDonough (2008, p. 72), os objetivos fornecem "direcionamento aos colaboradores e participantes envolvidos na tarefa de tornar o evento bem-sucedido - ajuda-os a manter o rumo".

Para este estudo, foram escolhidos os eventos de integração, treinamentos, festas de confraternização, incentivos, palestras e competições, para se verificar a influência que as políticas de eventos corporativos têm sobre as pessoas no ambiente de trabalho.

Assim, neste trabalho, considerou-se importante apresentar os conceitos de organização e de comportamento organizacional. Para tal considera-se que ao compreender o comportamento humano dentro da organização é possível administrá-lo, de forma a obter um desempenho organizacional mais eficiente e eficaz. Contudo, entender o conceito de comportamento

Revista de Gestão e Secretariado - GeSec, São Paulo, v. 5, n. 1, p 131-145, jan./abr. 2014. 
organizacional não basta, pois este está intimamente ligado ao de clima organizacional, que diz respeito ao estado de satisfação das pessoas de uma empresa.

As políticas de recursos humanos voltadas à satisfação de seu público interno são suportadas por uma divisão do marketing chamado endomarketing. Por isso, optou-se por apresentar a definição de políticas de recursos humanos e de endomarketing, o que será realizado no próximo tópico.

\subsection{COMPORTAMENTO ORGANIZACIONAL, MOTIVAÇÃO E ENDOMARKETING}

O estudo do comportamento organizacional é relativamente novo, tendo suas bases científicas apoiadas nas ciências sociais da psicologia e antropologia, como também na economia, sociologia e ciências políticas. Segundo Greiner (1967), “O comportamento organizacional definido nesses termos tem suas origens no final dos anos 1940, quando os pesquisadores das áreas de psicologia, sociologia, ciência política, economia e de outras ciências sociais procuravam desenvolver uma estrutura unificada de pesquisas organizacionais."

Assim, as primeiras delimitações do campo de Comportamento Organizacional surgiram nos anos de 1960, quando Pugh (1969) o definiu como estudo da estrutura e do funcionamento das organizações e do comportamento dos indivíduos e grupos dentro delas, ao defender que se trata de uma ciência apoiada em disciplinas como Psicologia, Sociologia e Economia.

No cenário competitivo de hoje, é fundamental que se adote uma abordagem estratégica do comportamento organizacional, baseando-se na premissa de que o alicerce das vantagens competitivas de uma organização é representado pelas pessoas. É o que acreditam Colella, Hitt e Miller (2007), ao afirmarem que:

\footnotetext{
Uma organização pode apresentar produtos e serviços de qualidade excepcionalmente elevada, um excelente nível de prestação de serviços ao consumidor, a melhor estrutura de custos da classe, ou alguma outra vantagem, porém todos eles representam produtos das competências das pessoas dentro da organização - o seu capital humano. Se forem organizados e administrados de maneira eficaz, o conhecimento e as competências das pessoas na organização conduzem a uma vantagem competitiva sustentável e a um sucesso financeiro de longo prazo. (Colella, Hitt \& Miller, 2007, p. 5)
}

Portanto, seguir uma abordagem estratégica do comportamento organizacional significa compreender, dar valor e efetivamente impulsionar as pessoas, de modo a administrar seus conhecimentos e competências de maneira eficaz, a fim de implementar a estratégia da organização 
e conquistar vantagem competitiva (Colella, Hitt \& Miller, 2007).

Sabe-se que a motivação é um processo interno ao indivíduo, mas o ambiente contribui por meio de estímulos positivos ou negativos para seu afloramento, pois é a partir dele que o homem constrói, pela percepção, sua realidade. Para McClelland (1972), o clima organizacional é determinado pelos estilos de liderança e administração, bem como pela estrutura organizacional, que contribui para moldar o comportamento dos indivíduos. Ou seja, o clima organizacional é uma qualidade do ambiente da organização que pode ser percebida pelos seus membros e influencia em seu comportamento.

Ao reconhecer como as pessoas percebem a extensão do ambiente em que estão inseridas, a qualidade das intervenções dos gestores poderá ser melhorada, conforme aponta McClelland (1972). Ainda para o autor, é por meio do clima organizacional que eles podem "administrar a motivação" de seus empregados, ampliar a eficácia organizacional e, ao mesmo tempo, canalizar o comportamento motivado para os objetivos organizacionais.

Souza e Santos (1992) afirmam que uma estratégia que tem sido aplicada com essa finalidade é a utilização do marketing junto ao público interno da organização, ou seja, o endomarketing. Com o foco nos funcionários, tratando-os como clientes internos, a área de Recursos Humanos - RH coloca em prática o endomarketing. Um dos seus principais objetivos consiste em atrair e manter talentos para a empresa, o que coincide com o objetivo de RH. O endomarketing consiste em um desdobramento do marketing que tem como foco o público interno da empresa. Tal estratégia é claramente expressa pelo significado semântico da palavra. Segundo França (2008, p. 149) “o prefixo endo significa 'para dentro, dentro de', que dá a ideia de interiorização, de algo que se move para dentro de si, de uma ação interior de algo”. Sob esta nova ótica, os funcionários passam a ser tratados como clientes, possuidores de necessidades que devem ser identificadas e supridas. Segundo Cobra e Brezzo (2010, p. 176), “o que 'vendemos' nesse caso é a adesão à empresa integrada do ponto de vista dos funcionários pelas condições de contratação, as relações do trabalho, o ambiente de trabalho etc.". Como resultado, tem-se o aumento da qualidade dos bens e serviços e da produtividade de pessoas e processos, que acarretam na satisfação do cliente final (Bekin, 1995).

Gonroos (apud Ponce, 1995) afirma que o endomarketing se compõe de várias atividades, muitas das quais não são novas nem restritas a ele, mas que são geridas de forma integrada e estratégica. Pode-se dizer que o endomarketing é um modelo de gestão de pessoas que faz uso de conceitos e técnicas de marketing. Ele deve promover a integração, a cooperação, o tratamento de conflitos, a motivação, a satisfação e o comprometimento no interior da organização, estando assim, ligado ao conceito de clima organizacional (França, 2008).

Revista de Gestão e Secretariado - GeSec, São Paulo, v. 5, n. 1, p 131-145, jan./abr. 2014. 
De acordo com Bekin (1995), a maior contribuição do endomarketing talvez esteja na ênfase dada à avaliação e ao aprimoramento do ambiente interno da organização. A relação desempenho, recompensas e satisfação alimentam a motivação, e para que ela ocorra, deve-se oferecer um produto que corresponda às expectativas de qualidade do funcionário, o que exige a captação de sua própria percepção, o que significa ter de conhecê-lo a fundo - seus interesses, valores, crenças, princípios.

\section{METODOLOGIA DE PESQUISA}

O objetivo deste artigo é verificar o impacto que as políticas de eventos têm sobre o clima organizacional. Para a análise deste impacto, foram realizadas duas etapas de pesquisa, uma de natureza exploratória e outra de natureza quantitativa descritiva. Na primeira fase, valeu-se da pesquisa exploratória que foi realizada com base no método de levantamento bibliográfico, a fim de desenvolver melhor conhecimento sobre o assunto, corroborando o que argumentam Acevedo e Nohara (2010), uma vez que as autoras consideram que a pesquisa exploratória proporciona maior compreensão sobre o fenômeno estudado e permite maior precisão na delimitação do problema.

Em uma segunda etapa, desenvolveu-se uma pesquisa quantitativa descritiva, por meio da técnica de levantamento de campo, com a finalidade de identificar os efeitos que as políticas e práticas de eventos, ou até mesmo a ausência destas, provocam nos colaboradores, interferindo em seu grau de motivação e interação. Segundo Bervian, Cervo e Silva (2009), a pesquisa descritiva pode ser utilizada para observar, registrar, analisar e correlacionar fatos ou fenômenos (variáveis) sem manipulá-los. Tenta descobrir com que frequência um fenômeno ocorre, sua relação com outros, sua natureza e suas características.

A população pesquisada foi composta por 63 funcionários de empresas da grande São Paulo, sendo composto por $67 \%$ de público feminino, $49 \%$ na faixa etária entre 18 e 25 anos. A definição do público se deu pelo acesso das autoras a estes, assim todos os respondentes eram alunos do curso de Automação de Escritórios e Secretariado da Faculdade de Tecnologia de São Paulo - Fatec-SP.

$\mathrm{O}$ instrumento de coleta de dados foi um questionário fechado, com questões objetivas de múltipla escolha. A análise realizada foi quantitativa.

Revista de Gestão e Secretariado - GeSec, São Paulo, v. 5, n. 1, p 131-145, jan./abr. 2014. 


\section{ANÁLISE E DISCUSSÃO DOS RESULTADOS}

Neste tópico, os resultados da pesquisa quantitativa são apresentados por meio de gráficos seguidos das respectivas análises, relacionando em alguns momentos com as considerações obtidas por meio da pesquisa exploratória.

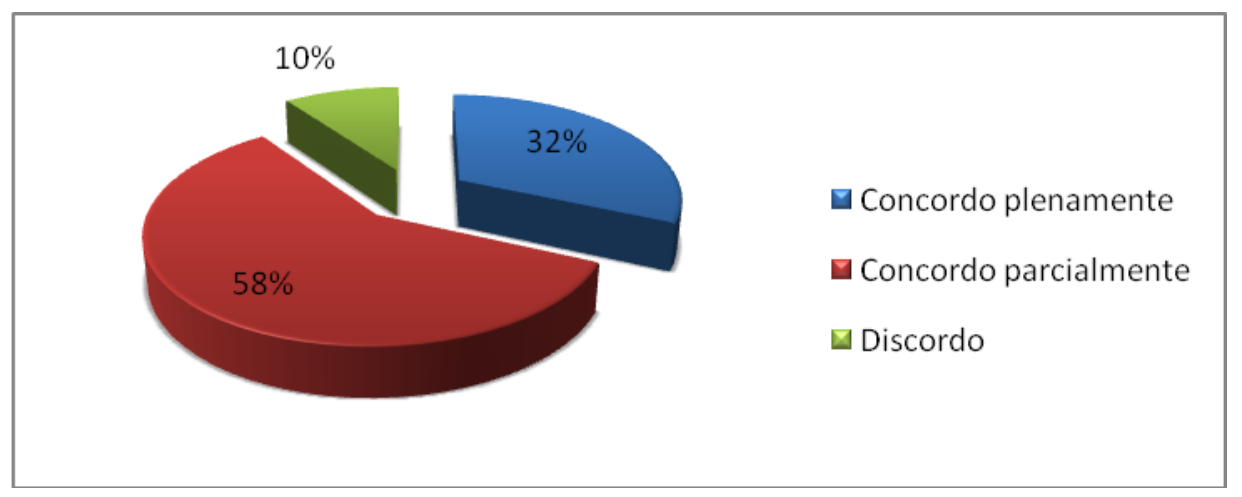

Gráfico 1 - Existe preocupação com os funcionários dentro das políticas de recursos humanos adotadas na empresa.

Fonte: Elaborado pelas autoras.

O levantamento bibliográfico aponta que as empresas se preocupam com a satisfação de sua força de trabalho. Apesar disso, a pesquisa quantitativa concluiu que para $32 \%$ dos respondentes concordam plenamente que as empresas têm uma preocupação com os funcionários. Quase 2/3 dos respondentes concordaram parcialmente com a afirmação, o que demonstra uma divergência nas percepções das empresas e dos funcionários.

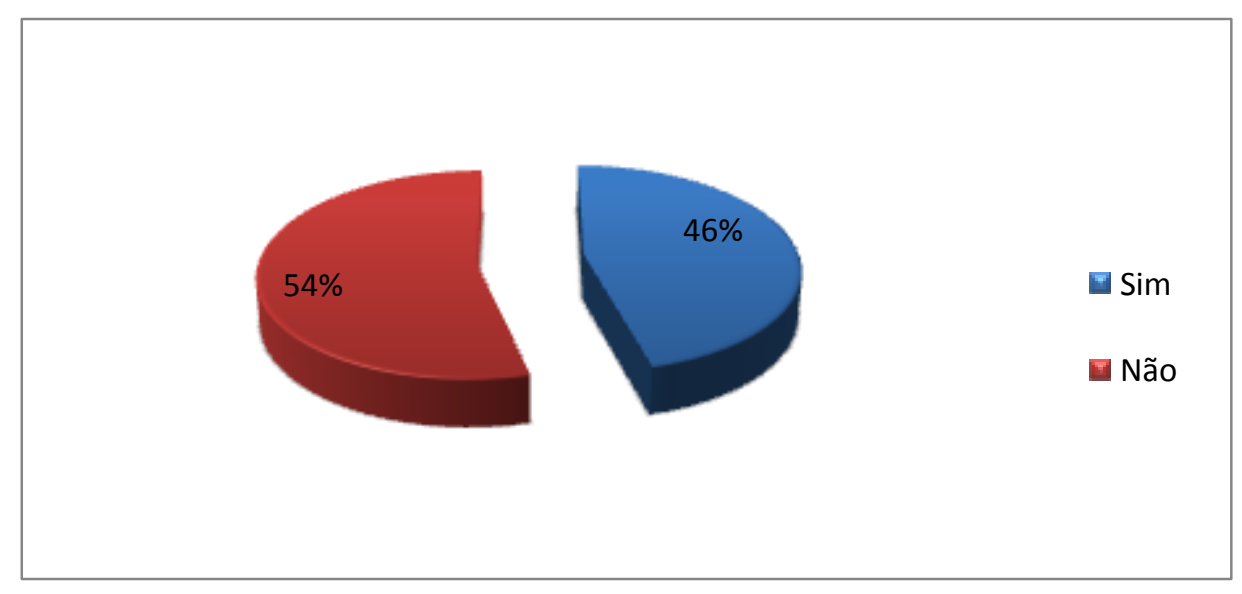

Gráfico 2 - Conhecimento da existência de políticas de eventos.

Fonte: Elaborado pelas autoras.

Revista de Gestão e Secretariado - GeSec, São Paulo, v. 5, n. 1, p 131-145, jan./abr. 2014. 
Complementando a percepção dos funcionários quanto à baixa preocupação da empresa com a satisfação destes, a questão seguinte apontou que mais da metade dos respondentes, ou seja 54\% desconhecem iniciativas relacionadas às políticas de eventos. Assim, embora tais políticas existam, parece ser necessária uma divulgação mais ampla, papel relacionado ao endomarketing.

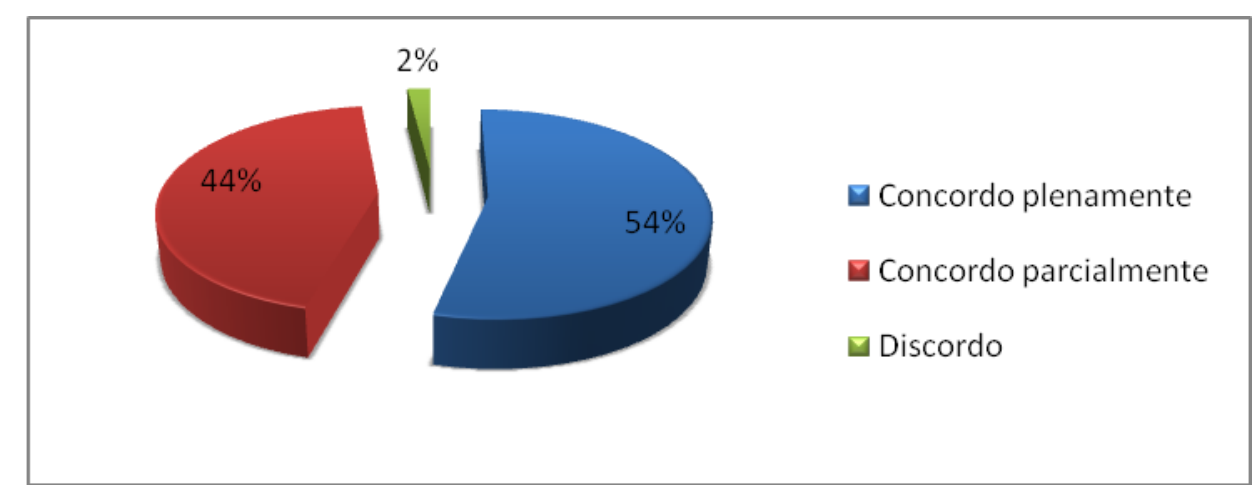

Gráfico 3 - Você acredita que as políticas de eventos influenciam no nível de motivação e integração dos funcionários.

Fonte: Elaborado pelas autoras.

No gráfico 3 pode-se observar que quase a totalidade dos respondentes acredita que as políticas de eventos influenciam o nível de motivação, bem como a integração dos funcionários, ainda que $44 \%$ concordem parcialmente com a afirmação.

O próximo gráfico (4), a questão formatada procurou verificar a influência da política de eventos no clima organizacional, ao que 77\%, dos respondentes concordaram plenamente. Assim, é possível perceber que as políticas de eventos fazem parte dos fatores que podem alavancar a satisfação dos funcionários de uma empresa. E, por isso, as autoras acreditam ser relevante que as organizações tratem o tema com mais seriedade e comprometimento.

Revista de Gestão e Secretariado - GeSec, São Paulo, v. 5, n. 1, p 131-145, jan./abr. 2014. 


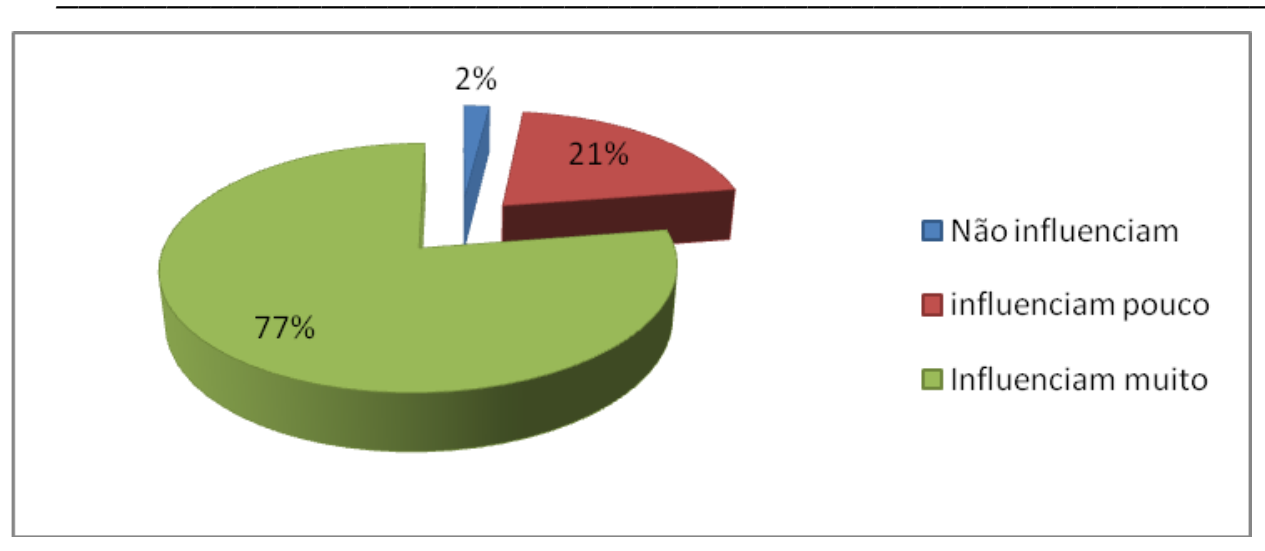

Gráfico 4 - Influência das práticas de eventos no clima organizacional. Fonte: Elaborado pelas autoras.

Em seguida, verificou-se a frequência com que alguns tipos de eventos são realizados nas empresas em que os respondentes trabalham. Os eventos citados foram: treinamentos, festas de confraternização, palestras, eventos de incentivos, competições (funcionário do mês, concursos literários etc.) e eventos de integração (cafés da manhã, aniversários etc.).

A opção "nunca" liderou, com 63\% de respostas, seguida pelos eventos de incentivo, com 43\%. Esse resultado nos permite afirmar que as empresas não utilizam de um meio de interação saudável entre os seus indivíduos para alavancar resultados e promover o crescimento profissional e organizacional, deixando de lado ainda um fator importantíssimo no processo de motivação, o reconhecimento e o incentivo pelo bom trabalho realizado. Com uma influência considerada "média", chega a números muito próximos. Palestras e eventos de integração com 35\%, competições com $33 \%$ e eventos de incentivos com $32 \%$. Treinamentos foram eleitos com $62 \%$ como o tipo de evento com maior influência no clima da empresa.

Esses dados direcionam novamente para o investimento na qualificação de pessoal e no impacto que esse tipo de evento exerce na motivação dos funcionários.

Revista de Gestão e Secretariado - GeSec, São Paulo, v. 5, n. 1, p 131-145, jan./abr. 2014. 


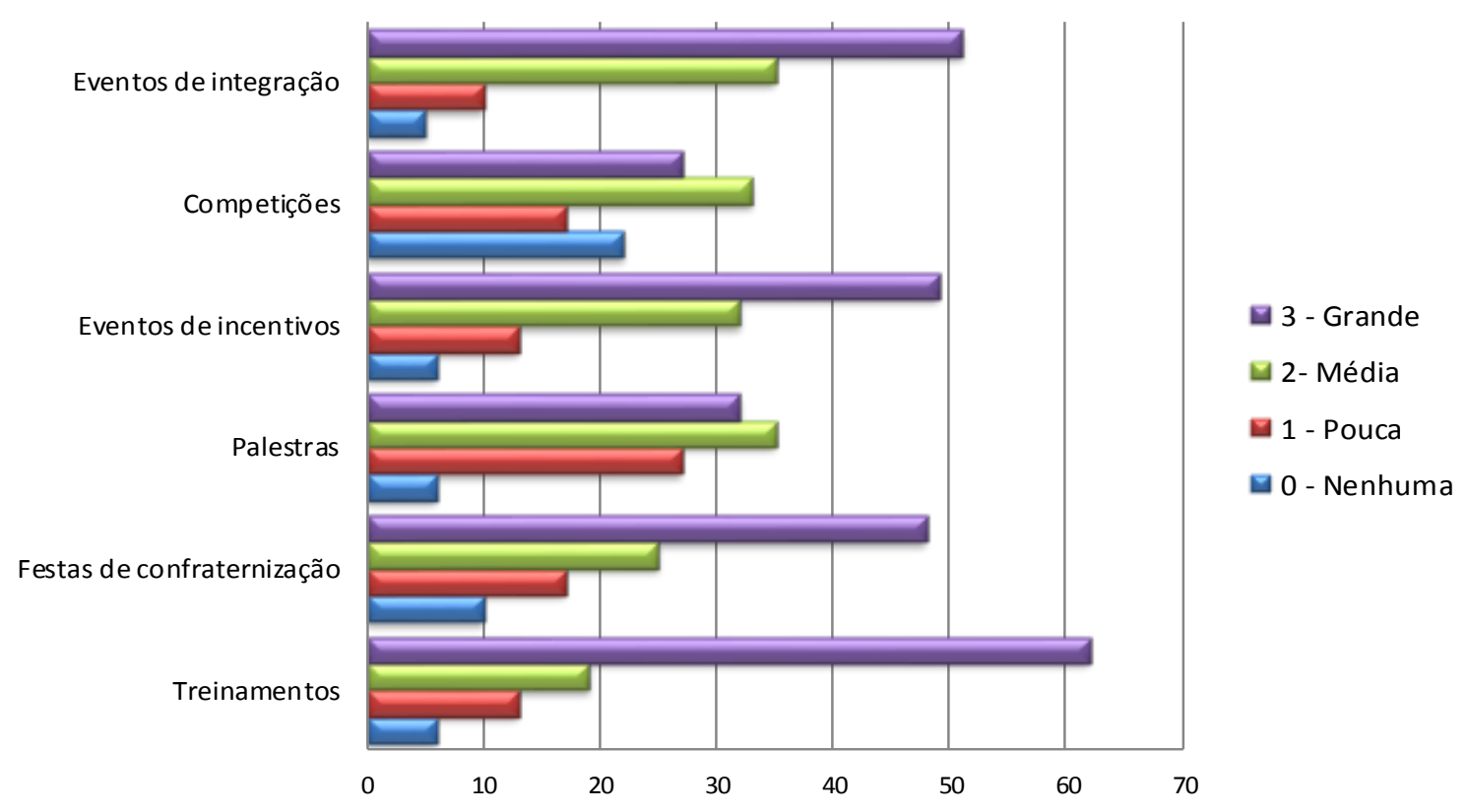

Gráfico 5 - Eventos e sua influência no clima organizacional. Fonte: Elaborado pelas autoras.

Ao focar uma cultura organizacional participativa e democrática, foi levantada a questão da motivação causada por eventos corporativos. A maior parte das pessoas concorda que essa motivação transforma a cultura da empresa em um ambiente onde podem se expressar mais, com a participação e a democratização do processos. Dessa maioria, 56\% concordam plenamente e $43 \%$ parcialmente, que denota que outros fatores também fazem parte desse processo.

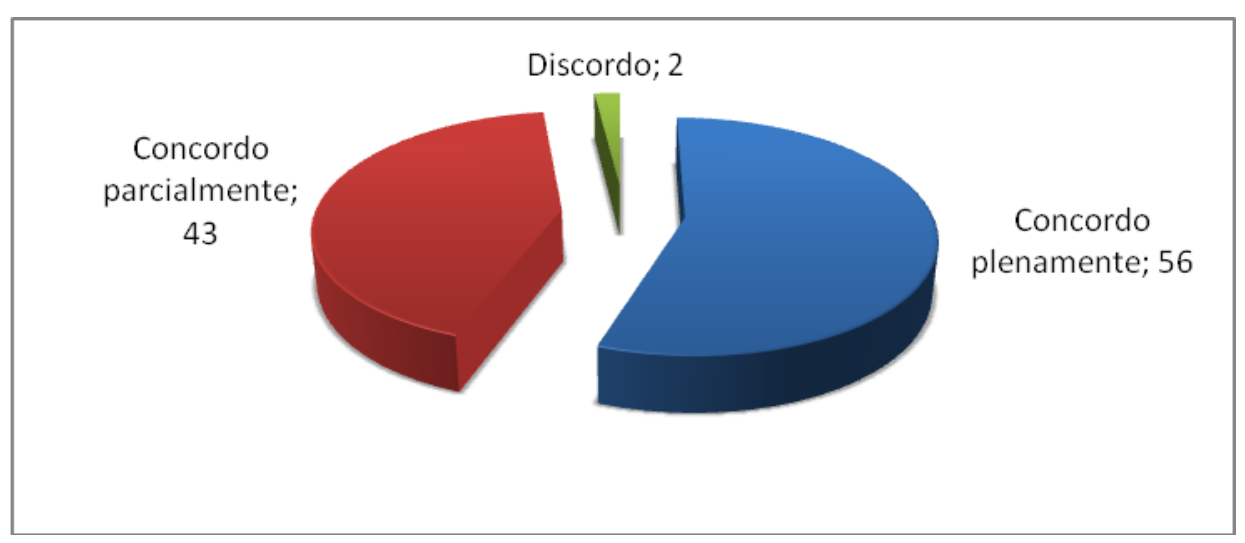

Gráfico 6 - Uma cultura organizacional mais participativa e democrática como reflexo da motivação causada por eventos corporativos.

Fonte: Elaborado pelas autoras.

Revista de Gestão e Secretariado - GeSec, São Paulo, v. 5, n. 1, p 131-145, jan./abr. 2014. 
Dos respondentes da pesquisa, $68 \%$ acreditam que deveria haver maior preocupação com os funcionários dentro das políticas de recursos humanos adotadas nas empresas em que trabalham. Isso mostra que as organizações não priorizam as necessidades e expectativas de seus funcionários, esquecendo-se que eles são recursos essenciais para toda e qualquer atividade. As organizações estão inseridas dentro de um contexto social e cultural, do qual recebem influências e influenciam. Administrar essas influências, por meio de intervenções no clima e no comportamento organizacional, é fundamental para que atuem com eficiência.

Questionados sobre a influência das práticas de eventos no clima organizacional, 79\% responderam influenciar muito. Apesar disso, apenas $46 \%$ dos respondentes identificam tais políticas e práticas em suas empresas. Isso demonstra que embora os colaboradores reconheçam que seu nível de motivação e integração seja elevado com a aplicação de práticas de eventos e, além disso, afirmem que há influência destas práticas em todo o clima da organização, são poucas as empresas que as adotam como ferramenta estratégica.

Ainda quanto às práticas e políticas de eventos, procurou-se observar alguns tipos eventos coorporativos específicos, como: treinamentos, festas de confraternização, palestras, eventos de incentivos, competições e eventos de integração. Constatou-se que embora grande parte dos respondentes considere que tais eventos tenham média ou grande influência no clima organizacional, a frequência com que ocorrem muitas vezes é baixa ou menor do que a ideal. Por exemplo, os eventos de incentivo receberam grau 3 de influência de $49 \%$ dos respondentes, entretanto, nas empresas de $43 \%$ dos respondentes esse tipo de evento nunca ocorre e em $19 \%$ ocorrem apenas semestralmente. O campeão em frequência são os eventos de integração, acontecendo mensalmente em $37 \%$ das empresas onde os respondentes trabalham. É, também, vicecampeão no quesito influência no clima organizacional, com $51 \%$ de respostas classificando-o com grau 3. Com isso, percebe-se que existe grande disparidade entre a frequência e a influência desses eventos no cenário corporativo, embora haja exceções. As organizações, mais uma vez, demonstram não saber a opinião de seus colaboradores, perdendo a chance de melhorar o clima organizacional e, consequentemente, o desempenho organizacional.

Continuando com o foco na relação entre a motivação e as políticas de eventos, entre os $46 \%$ que responderam conhecer a existência de políticas de eventos em suas empresas, 52\% concordam plenamente e $48 \%$ parcialmente que existe sim uma interferência dessas políticas em seu nível de motivação e integração com outros funcionários. Surpreendentemente, entre os 54\% dos respondentes que desconhecem a aplicação dessas práticas no local onde trabalham, 59\% também concordam plenamente com a interferência sugerida. Essas informações indicam que se as

Revista de Gestão e Secretariado - GeSec, São Paulo, v. 5, n. 1, p 131-145, jan./abr. 2014. 
organizações investissem nos eventos corporativos com o foco nos funcionários, conseguiriam elevar estado de motivação de seus colaboradores.

Entre os 63 respondentes, independente da existência ou não de práticas e políticas de eventos em suas empresas, dos $54 \%$ que concordam plenamente com a incidência de uma influência na motivação por parte destas práticas, $51 \%$ atribuíram grau 5 na classificação do fator motivacional Treinamentos e Eventos. Dos $44 \%$ que concordam parcialmente, $25 \%$ atribuíram grau 5 e dos 2\% que discordam, curiosamente, $100 \%$ atribuíram grau 4. Esses dados também demonstram que treinamentos e eventos são um importante fator motivacional, embora não seja o fator principal e devam estar associados a outros, para se alcançar uma motivação efetiva

\section{CONSIDERAÇÕES FINAIS}

Para que o evento atenda às expectativas do seu idealizador e do público, é necessário identificar quais objetivos devem ser atingidos. Dependendo do foco e da magnitude do evento, poderá ser estabelecido mais de um objetivo. Eventos projetados com foco na satisfação dos funcionários despertam no indivíduo um sentimento de reconhecimento e integração, fazendo com que este se sinta parte importante e fundamental da organização. Colaboradores satisfeitos com ambiente e benefícios oferecidos trabalham em sintonia com os objetivos e metas da empresa e mantêm um clima organizacional favorável.

Por trás de um evento bem organizado, existe o trabalho conjunto de uma equipe gerenciada por um, ou mais, profissional especializado. As articulistas acreditam que este pode ser da área de Marketing, Relações Públicas, Recursos Humanos e/ou Secretariado.

Em cenários competitivos, cada vez mais é preciso informar, motivar e desenvolver relacionamentos com clientes, fornecedores e funcionários. Com a finalidade de ampliar a esfera de relacionamentos inerentes ao convívio no trabalho, e de quebrar a rotina dos afazeres cotidianos, as organizações utilizam com maior ênfase eventos para promover a integração e até mesmo a motivação e reconhecimento de seus funcionários.

Dessa forma, se for conveniente e proporcionar melhorias significativas no clima organizacional, aplica-se uma política de eventos voltada aos funcionários. Por isso, as autoras consideram importante a participação da área de Recursos Humanos, na identificação das necessidades dos funcionários, e qual é a melhor forma de atendê-las. 
Por outro lado, para que haja o adequado retorno sobre o investimento, considera-se que a área de marketing deve ser engajada, para possibilitar o melhor desenvolvimento do endomarketing.

Com a definição de eventos e políticas de eventos, organização, comportamento organizacional, clima organizacional, motivação, políticas de recursos humanos e endomarketing, construiu-se o referencial teórico referente ao objeto de estudo. Isso possibilitou concluir que, embora a literatura pesquisada não aborde especificamente a questão da aplicação de práticas e políticas de eventos para se obter melhorias no clima organizacional, ela possibilita fazer relações que conduzem a tal afirmação.

Para estudos futuros, sugere-se levantar informações com uma amostra maior, já previamente selecionada, em duas situações diferentes: 1) colaboradores que trabalham em empresas que possuem políticas de eventos e 2) colaboradores que trabalham em empresas que não possuem políticas de eventos. Dessa forma, pode-se fazer uma análise de como esse fator, isoladamente, influência o clima organizacional.

\section{REFERÊNCIAS}

Bekin, Saul Faingaus. (1995). Conversando sobre endomarketing. São Paulo: Makron Books.

Bervian, Pedro Alcino; Silva, Roberto da \& Cervo, Amado Luiz (2007). Metodologia Cientifica. (6a ed.) São Paulo: Pearson Prentice Hall.

Bohlander, G.; Snell, Scott \& Sherman, Arthur. (2005). Administração de Recursos Humanos. São Paulo: Pioneira Thomson Learning.

Cesca, Cleuza G. Gimenes (2008). Organização de eventos: manual para planejamento e execução. São Paulo. Summus Editorial.

Cobra, Marcos \& Brezzo, Roberto (2010). O novo marketing. Rio de Janeiro: Elsevier.

Revista de Gestão e Secretariado - GeSec, São Paulo, v. 5, n. 1, p 131-145, jan./abr. 2014. 
França, Limongi (2008). Práticas de Recursos Humanos: PRH. São Paulo: Atlas.

Greiner, Larry. (1967). Patterns of organizations change. Harvard Business Review, May/June 1967. pp. 119-122.

Hitt, M. A.; Ireland, R. D. \& Hoskis Son, R. E. (2002) Administração estratégica. São Paulo: Pioneira Thomson Learning.

Hitt, Michael A.; Miller, C. Chet \& Colella, Adrienne (2007). Comportamento organizacional: uma abordagem estratégica. Rio de Janeiro: LTC.

Luz, Ricardo (2001). Clima organizacional. Rio de Janeiro: Qualitymark.

Mcclelland, D. C. (1972). A sociedade competitiva : realização e progresso social. Rio de Janeiro: Expansão e Cultura.

Moscovici, Fela (1997). Desenvolvimento interpessoal: treinamento em grupo. Rio de Janeiro: José Olympio.

Phillips, Jack J.; Myhill Monica; \& Mcdonough James (2001). B. Valor estratégico dos eventos: como e por que medir ROI. São Paulo: Aleph.

Ponce, Felicia Alejandrina Urbina. (1995). Marketing Interno: um estudo de caso no setor de franqueado do ramo de perfumaria e cosmético nas cidades de São Paulo e Osasco. Tese de Doutorado, Faculdade de Economia, Administração e Contabilidade, Universidade de São Paulo, São Paulo.

Pugh, D. S. (1969). Organization theory: An approach from psychology. Human Relations, 22, 345354.

Souza, A. \& Santos, G. (1992). Endomarketing: considerações teóricas e práticas de uma estratégia de integração. In: ANPAD, Marketing, vol. 5. Rio Grande do Sul.

Andrade, Renato Brenol. (1999). Manual de eventos. Caxias do Sul: Educs.

Acevedo, Claudia Rosa; Nohara, Jouliana Jordan. (2010). Monografia no curso de administração: guia completo de conteúdo e forma: inclui normas atualizadas da ABNT, TCC, TGI, trabalhos de estágio, MBA, dissertações, teses. 3 ed. São Paulo: Atlas. 